\title{
AVALIAÇÃO DA ATIVIDADE in vitro DO FIPRONIL CONTRA LARVAS NÃO ALIMENTADAS DE Dermacentor nitens
}

\author{
(Evaluation of the in vitro efficacy of fipronil against not engorged larvae of Dermacentor nitens)
}

Marisa Beatriz da Silva Rocha, Brena Gava Guimarães, Roxanne Marina da Silva Roque, Daniela de Oliveira Rocha, Andressa Aparecida de Lima Reis, Thais Paes Ferreira, Barbara Rauta de Avelar, Fabio Barbour Scott

Universidade Federal Rural do Rio de Janeiro, Rio de Janeiro, Brasil.

\author{
*Correspondência: brenagava@hotmail.com
}

RESUMO: O carrapato Dermacentor nitens parasita preferencialmente equinos e é popularmente conhecido como carrapato da orelha dos cavalos. A infestação por este parasito promove prejuízos ao animal pela espoliação sanguínea, queda na produtividade, predisposição ao aparecimento de miíases e infecções bacterianas secundárias, além de ser vetor do protozoário Babesia caballi, agente causador da babesiose equina. Assim, o objetivo deste trabalho é avaliar a atividade acaricida in vitro do fipronil, em três diferentes metodologias, contra larvas não alimentadas de $D$. nitens. Os ensaios foram realizados em duplicata, com larvas não alimentadas de 17 dias, obtidas na colônia do Laboratório de Quimioterapia Experimental em Parasitologia Veterinária (LQEPV) no Instituto de Veterinária (IV) da Universidade Federal Rural do Rio de Janeiro (UFRRJ). As seguintes concentrações de fipronil foram testadas: $1 ; 2,5 ; 5 ; 10 ; 20 ; 40 ; 60 ; 80$ e 100 ppm, obtidas a partir da diluição de fipronil técnico em água e triton-x para as metodologias de imersão larval (LIT) e de LIT adaptado, e em azeite de oliva extra virgem e tricloroetileno (2:1) para a metodologia de pacote de larvas (LPT). Na metodologia LIT, 300 larvas foram imersas em um microtubo com $1 \mathrm{~mL}$ de solução por 10 minutos. Após drenar a solução, as larvas foram secas e aproximadamente 100 colocadas em envelope de papel filtro $(6 \times 6 \mathrm{~cm})$. Para LIT adaptado, aproximadamente 100 larvas foram depositadas em um sanduíche de papel filtro $(2 \times 2 \mathrm{~cm})$ impregnado com $500 \mu \mathrm{L}$ da solução. Cada sanduíche foi acondicionado em envelope de papel filtro $(6 \times 6 \mathrm{~cm})$. E para LPT, o papel filtro $(8,5 \times 7,5 \mathrm{~cm})$ foi previamente impregnado com $670 \mu \mathrm{L}$ de solução. Após duas horas de secagem, foram feitos envelopes e cerca de 100 larvas foram alocadas em cada. Para as três metodologias, o armazenamento foi feito em estufa climatizada com demanda controlada de oxigênio a $27^{\circ} \mathrm{C}$ e 80\% UR. Após 24 horas foi realizada leitura para avaliação da mortalidade, de acordo com a seguinte fórmula: \% de mortalidade $=$ total de larvas mortas $\times 100 /$ total de larvas. Os dados encontrados foram tabulados e os valores das concentrações letais $\mathrm{CL}_{50}$ e $\mathrm{CL}_{90}$ foram calculadas estatisticamente por meio da análise Probit utilizando o programa computacional $\mathrm{R}$ versão 3.6.1. Para LIT, a $\mathrm{CL}_{50}$ foi de 3,04 ppm (2,36-3,77 ppm), e a $\mathrm{CL}_{90}$ de 22,29 ppm (17,94-28,77 ppm). O slope obtido foi de $1,481 \pm 0,334$ e o R de 0,584. Enquanto LIT adaptado, a $C_{50}$ foi de $14,32 \mathrm{ppm}$ (12,79-15,98 ppm), e a $\mathrm{CL}_{90}$ de 49,19 ppm (42,48-58,30 ppm), e em LPT a $\mathrm{CL}_{50}$ foi de 20,77 ppm (18,50-23,33 ppm), e a $\mathrm{CL}_{90}$ de $80,06 \mathrm{ppm}(67,63-97,58 \mathrm{ppm})$, maiores que as obtidas em LIT. O slope obtido foi de 2,391 $\pm 0,130$ e o R de 0,899 para LIT adaptado, e para LPT o slope foi de $2,187 \pm 0,418$ e o $R$ de 0,973 . Portanto, o fipronil demonstrou ação larvicida in vitro contra $D$. nitens nas concentrações avaliadas, tornando este fenilpirazol um provável ativo utilizado para o controle deste carrapato, além de LIT ter sido a metodologia mais sensível em que se obteve as menores CLs para o fipronil.

Palavras-chave acaricida; carrapato; controle; fenilpirazol.

\section{Agradecimentos}

Ao LQEPV pelo suporte na realização dos experimentos e às agências de fomento: Fundação de Apoio à Pesquisa Científica e Tecnológica da UFRRJ (FAPUR), Ministério da Educação (MEC), Coordenação de Aperfeiçoamento de Pessoal de Nível Superior (CAPES) e Conselho Nacional de Desenvolvimento Científico e Tecnológico (CNPq).

Nota: Aprovado pela Comissão de Ética no Uso de Animais (IV/UFRRJ) sob o número de protocolo 2524181218. 